\title{
Embedded Planar Power Inductor in an Organic Interposer for Package-Level DC Power Grid
}

\author{
Yuichiro Yazaki ${ }^{1}$, Kazuma Ishidate ${ }^{1}$, Kazuhiro Hagita' ${ }^{1}$, Yuta Kondo ${ }^{1}$, Saki Hattori ${ }^{1}$, Makoto Sonehara ${ }^{1}$, \\ Toshiro Sato ${ }^{1}$, Tetsuro Watanabe ${ }^{2}$, Yuto Seino ${ }^{2}$, and Nobuhiro Matsushita ${ }^{2}$
}

${ }^{1}$ Spin Device Technology Center, Shinshu University, Nagano 380-8553, Japan

${ }^{2}$ Materials and Structures Laboratory, Tokyo Institute of Technology, Yokohama 226-8503, Japan

\begin{abstract}
To realize the basic technology of a package-level dc power grid for the next generation power delivery to large scale integrated circuits (LSIs), two types of planar spiral inductors embedded in an organic interposer, for several tens of megahertz switching power supply integrated in LSI package, have been proposed. One is a $\mathrm{Zn}-\mathrm{Fe}$ ferrite core spiral inductor, and another is a hybrid core spiral inductor, with quasi closed magnetic circuit consisting of the bottom $\mathrm{Zn}$-Fe ferrite core and top carbonyl-iron/epoxy composite core. In this paper, the two types of planar spiral inductors have been fabricated and evaluated. From the experimental results, it was found that the hybrid core planar spiral inductor exhibited higher $Q$-factor and larger rating dc current than the $\mathrm{Zn}-\mathrm{Fe}$ ferrite core inductor.
\end{abstract}

Index Terms - Carbonyl-iron/epoxy composite, package-level power grid, planar power inductor, $\mathrm{Zn}-\mathrm{Fe}$ ferrite.

\section{INTRODUCTION}

IN RECENT years, dc power delivery to large scale integrated circuits (LSIs) has been going for a low-voltage/large current power supply, and the power line loss between power supply and LSIs has been increasing more and more. Such power loss is a serious issue, which causes a degradation of the power utilization efficiency. In the conventional stage, a power supply delivered dc power to the plural LSIs. Recently, the distributed power supply system called point of load (POL) has been widely employed. As one of the advantages, POL can make shorten the distance between the power supply and LSIs. Therefore, the power line loss can be reduced, and the power utilization efficiency can be increased.

Research and development on the power supply on chip technology has recently been very active [1]. For example, Hazucha et al. [2] reported a $233 \mathrm{MHz}$ switching 4-phase buck dc-dc converter chip 
developed by $90 \mathrm{~nm}$ complementary metal-oxide-semiconductor process, where four air-core chip inductors on package were used. Onizuka et al. [3] developed an on-chip buck converter for distributed power supply system, where an air-core inductor was also used. Although such air core inductors can be fabricated easily using metal process only, there are serious demerits, such as a low inductance, large footprint, and undesired electromagnetic interference (EMI) noise, owing to wide spread alternating magnetic flux. Therefore, to make the footprint small and suppress the EMI noise, a magnetic core should be used for integrated power inductor.

As already reported [4], we forecast that the next generation power delivery to LSIs will become a package-level dc power grid (PLPG). The PLPG will consist of a main buck dc-dc converter with large current inductor and several POL buck dc-dc converters for each application LSI. The POL converter will have an embedded power magnetics in a package, semiconductor switches, and control circuit. To realize the embedded power magnetics, we have developed a $\mathrm{Zn}-\mathrm{Fe}$ ferrite planar spiral inductor [5], [6] embedded in an organic interposer. In addition, we have developed a carbonyl-iron/epoxy composite core planar spiral inductor as an on-package power magnetics [4]. We consider that the metal composite magnetic core made by low-cost printing method is suitable for the large current inductor, because its low permeability contributes toward larger margin in the superimposed dc current characteristic.

In this paper, to realize the embedded power magnetics for the next generation PLPG, two types of spiral inductors embedded in the organic interposer have been fabricated. One is a $\mathrm{Zn}-\mathrm{Fe}$ ferrite core sandwich-structured planar inductor made by new simple fabrication procedure, and another is a hybrid core inductor having a bottom $\mathrm{Zn}-\mathrm{Fe}$ ferrite thick film core and an inner spiral coil embedded in the carbonyl-iron composite core.

\section{Magnetic Core Materials For EMbedded Planar SpiRAL INDUCtor IN ORGANIC INTERPOSER}

\section{A. Zn-Fe Ferrite Thick Film}

$\mathrm{Zn}$-Fe ferrite thick film core was made by a spin-spray method [7]. Since the spin-sprayed ferrite film is deposited using oxidizing solution and reaction solution at low temperature below $100{ }^{\circ} \mathrm{C}, \mathrm{Zn}-\mathrm{Fe}$ ferrite film synthesis does not give any thermal damage to the organic interposer. In this paper, chemical composition of $\mathrm{Zn}_{0.36} \mathrm{Fe}_{2.64} \mathrm{O}_{4}$ with high saturation magnetization of $0.57 \mathrm{~T}$ was selected to apply it to the power inductor.

As reported in the previous papers [6], [8], when the $\mathrm{Zn}-\mathrm{Fe}$ ferrite film was deposited on the epoxy/glass-filler build-up layer of the organic interposer, soft magnetic properties (coercive force and permeability) degraded owing to a few micrometer rough surface of the build-up layer. To obtain excellent 
soft magnetic properties, spin-sprayed ferrite film should have (111) orientation columnar grain structure. However, $\mathrm{Zn}-\mathrm{Fe}$ ferrite film deposited on the rough surface build-up layer did not have any columnar grain structure and exhibited random orientation grain growth. In this paper, to avoid the degradation of the soft magnetic properties of $\mathrm{Zn}-\mathrm{Fe}$ ferrite film on build-up layer, a polyimide planarization layer cured at low temperature of $180{ }^{\circ} \mathrm{C}$ (Kyocera Chemical Co., CT-4112) was introduced for underlayer of Zn-Fe ferrite.

Fig. 1 shows the static magnetization curve and complex permeability of $10 \mu \mathrm{m}$ thick $\mathrm{Zn}$-Fe ferrite film deposited on $3 \mu \mathrm{m}$ polyimide underlayer/build-up layer of organic interposer. $\mathrm{Zn}-\mathrm{Fe}$ ferrite film had a saturation magnetization $M_{s}$ of $0.57 \mathrm{~T}(5.7 \mathrm{kG})$, coercive force $H_{c}$ of about $1280 \mathrm{~A} / \mathrm{m}(16 \mathrm{Oe})$, low frequency relative permeability of 50 and natural resonant frequency of $300 \mathrm{MHz}$. From the complex permeability $v s$. frequency, $\mathrm{Zn}-\mathrm{Fe}$ ferrite thick film is suitable for power magnetics application at least up to several tens megahertz.

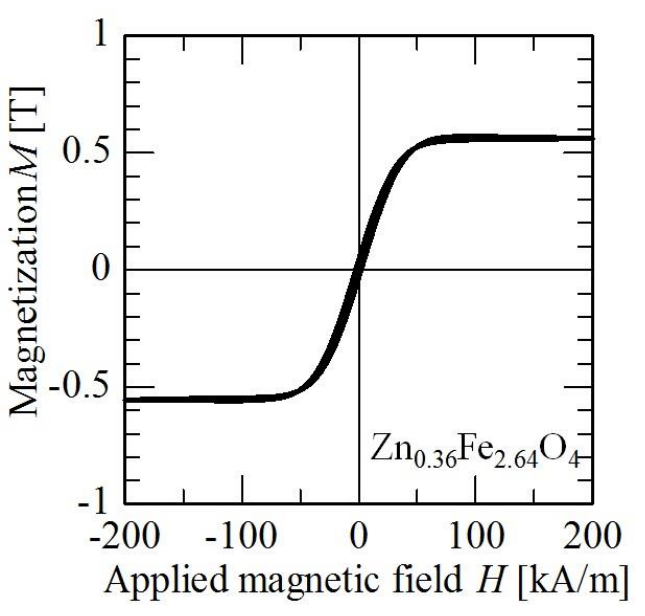

(a) Static magnetization curve

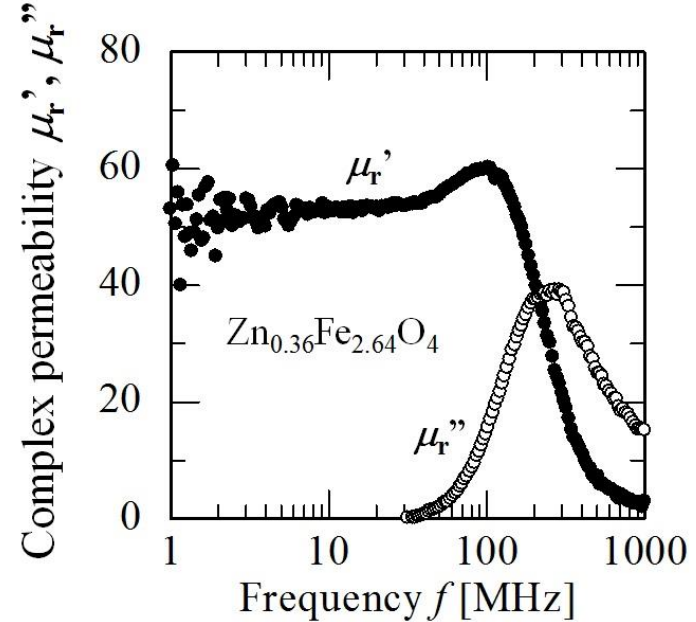

(b) Complex permeability

Fig. 1 Magnetic properties of spin-sprayed $10 \mu \mathrm{m}$ thick $\mathrm{Zn}$-Fe ferrite film deposited on $3 \mu \mathrm{m}$ polyimide underlayer/build-up layer of organic interposer [8]. 


\section{B. Carbonyl-Iron/Epoxy Composite Core}

1) Carbonyl-Iron Powder: Carbonyl-iron powder (CIP) was used for starting material for composite core. CIP made by BASF Co. was produced through thermal decomposition of iron-pentacarbonyl $\left(\mathrm{Fe}\left(\mathrm{CO}_{5}\right)\right)$. CIP used here was "Hard Grade", which was an as-decomposited powder without non-reduction. Typical specifications of the CIP are shown in Table 1. BASF Co. showed that the non-reduction CIP has an onion skin structure [9], which may be due to the spherical iron layers form on a nucleus in the Fe-particle growth, and CIP has a narrow particle-size distribution with a mean diameter of $1.1 \mu \mathrm{m}$.

Fig.2 shows the static magnetization curve of the CIP [4]. The CIP had a saturation magnetization of about $2 \mathrm{~T}$ and small coercive force. Such a small coercive force of $1000 \mathrm{~A} / \mathrm{m}(12.5 \mathrm{Oe})$ may be due to a small crystalline magnetic anisotropy based on the $20 \mathrm{~nm}$-size fine grain nanostructure [10], [11].

2) Carbonyl-Iron/Epoxy Composite Core: The composite core was composed of CIP and epoxy resin. The composite paste, consisted of CIP and epoxy precursor solution, was printed using $50 \mu \mathrm{m}$ thick SUS-304 metal mask and then fired at $140{ }^{\circ} \mathrm{C}$ in the air. Therefore the composite core fabrication does not

Table 1 Typical specifications of non reduction Carbonyl-iron powder [4].

\begin{tabular}{c|c}
\hline Composition wt.\% [9] & $\begin{array}{l}\mathrm{Fe} \text { content } ; \text { up to } 97.8 \%, \mathrm{C} ; 1.0 \%_{\text {max. }}, \\
\mathrm{N} ; 0.9 \%_{\text {max. }}, \mathrm{O} ; 0.5 \%_{\text {max. }}\end{array}$ \\
\hline Mean diameter [9] & $1.1 \mu \mathrm{m}$ \\
\hline Saturation magnetization & $2 \mathrm{~T}$ (measured using VSM $)$ \\
\hline Coercive force & $1 \mathrm{kA} / \mathrm{m}(12.5$ Oe, measured using VSM $)$ \\
\hline
\end{tabular}

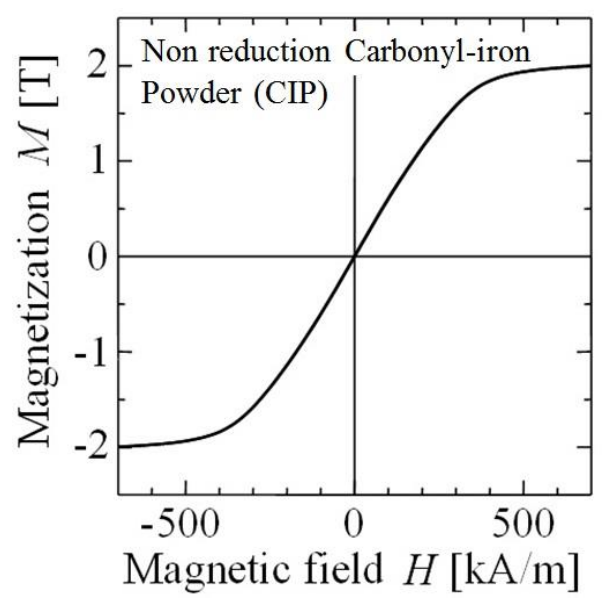

Fig. 2 Static magnetization curve of Carbonyl-iron powder [4]. 


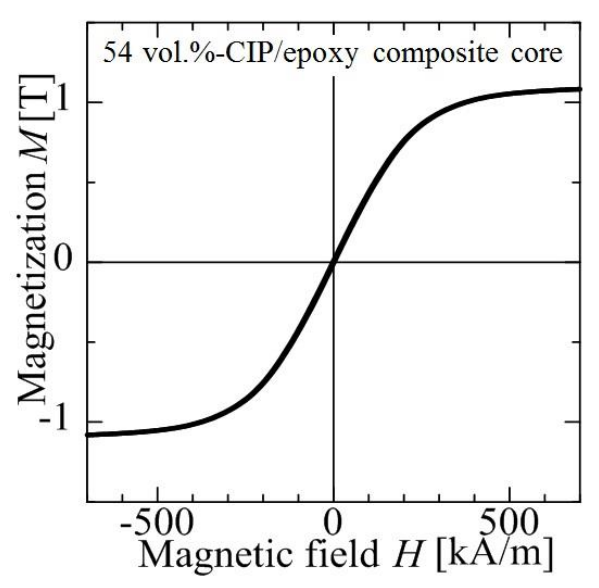

(a) Static magnetization curve

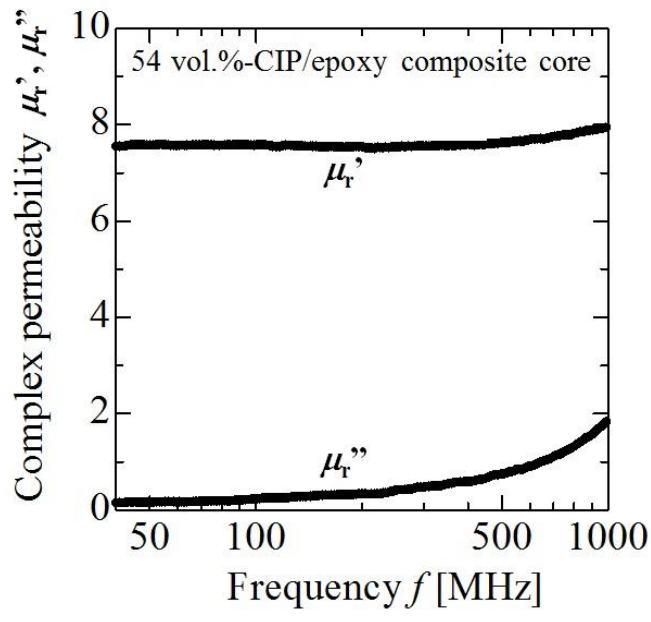

(b) Complex permeability

Fig. 3 Magnetic properties of 54 vol.\% Carbonyl-iron/epoxy composite core made by SUS-304 metal mask printing method.

give any thermal damage to the organic interposer as well as the ferrite synthesis. The viscosity of the CIP epoxy composite paste increased with increasing CIP volume fraction, and it was difficult to print the paste uniformly. Therefore, 54\%-CIP volume fraction in the post-fired composite core was upper limit when using the printing method.

Fig. 3 shows the static magnetization curve and complex permeability of the 54 vol.\% carbonyl-iron/epoxy composite core. As shown in the figure, the composite core exhibited a saturation magnetization of 1.08T, small coercive force of about $2 \mathrm{kA} / \mathrm{m}(25 \mathrm{Oe})$ and constant relative permeability of 7.5 up to around $500 \mathrm{MHz}$. Such a low permeability was considered to be due to the non-magnetic epoxy matrix (distributed air-gap).

\section{EMBEDDED PLANAR SPIRAL INDUCTORS}

\section{A. Embedded Planar Spiral Inductors in Organic Interposer}

An organic interposer used here was consisted of a $0.8 \mathrm{~mm}$ thick epoxy/glass-fiber center core and epoxy/glass-filler build-up layers, and two types of planar spiral inductors were embedded in interposer as shown in Fig. 4.

One is a $10 \mu \mathrm{m}$ thick $\mathrm{Zn}-\mathrm{Fe}$ ferrite core sandwich-structured planar spiral inductor with opened magnetic circuit. Another is a hybrid core inductor having a bottom $10 \mu \mathrm{m}$ thick $\mathrm{Zn}-\mathrm{Fe}$ ferrite film core and an inner spiral coil embedded in the CIP/epoxy composite core. By using CIP composite paste for top magnetic core on the spiral coil, quasi closed magnetic circuit can be established easily. In addition, since the $\mathrm{Zn}$-Fe ferrite film has good soft magnetic property when depositing it on flat surface, it has been used 


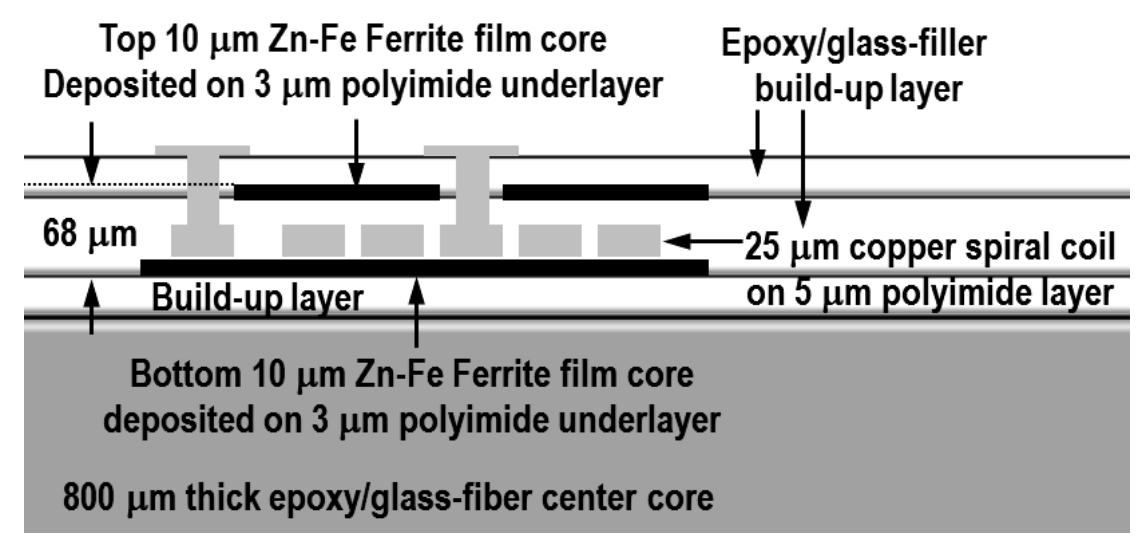

(a) Zn-Fe ferrite core planar spiral inductor

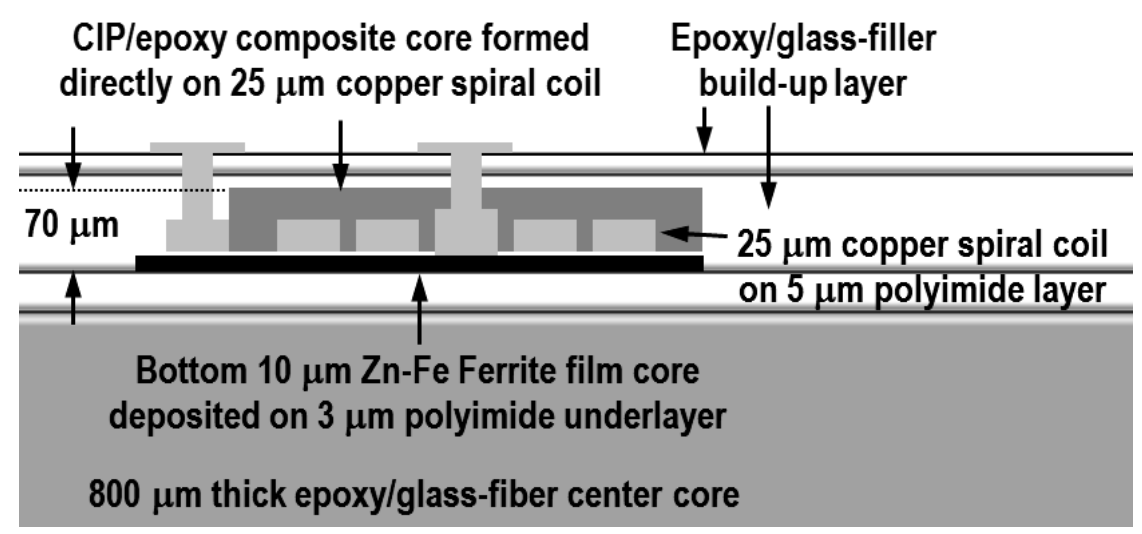

(b) Hybrid core planar spiral inductor

Fig. 4 Schematic cross-section of two types of embedded planar spiral inductors in organic interposer.

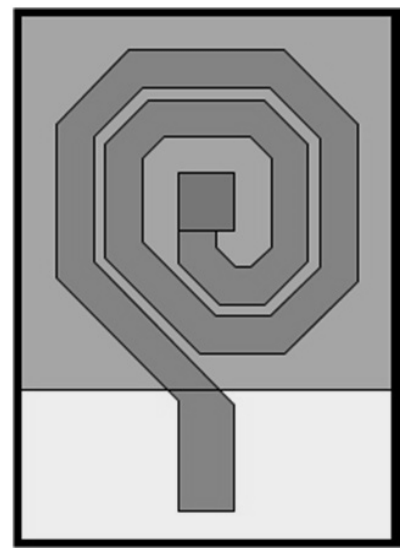

Copper spiral coil on bottom core

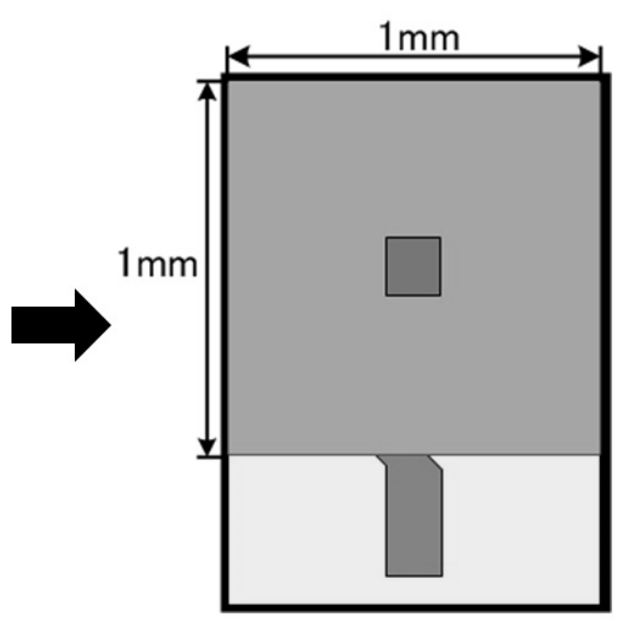

Top core formation

Fig. 5 Schematic top view of the embedded planar spiral inductors in organic interposer. 
for the bottom magnetic core. The quasi closed magnetic circuit having a structure of the low permeability composite core/thin polyimide air-gap/bottom $\mathrm{Zn}$-Fe ferrite core can be realized.

Detailed each layer thickness of the two types of planar spiral inductors is shown in Fig. 4. Fig. 5 shows a schematic top view of the embedded planar spiral inductors, their footprint is $1 \mathrm{~mm}^{2}$ in size.

\section{B. Inductor Fabrication Procedure}

Zn-Fe ferrite planar spiral inductor had a $25 \mu \mathrm{m}$ thick, 2-turn electroplated copper spiral coil sandwiched by the $10 \mu \mathrm{m}$ thick ferrite core. Spiral coil had a 100/30 $\mu \mathrm{m}$ line/space, $800 \mu \mathrm{m}^{2}$ in size and a dc resistance of $25 \mathrm{~m} \Omega$. The epoxy/glass-filler build-up layer is usually formed by thermal laminator in the organic interposer process. In our proposed ferrite inductor fabrication, $25 \mu \mathrm{m}$ thick spiral coil was planarized by the build-up layer laminated directly on spiral coil. The top and bottom Zn-Fe ferrite films were deposited on build-up layer through $3 \mu \mathrm{m}$ thick polyimide seed layer. The ferrite film was patterned using photo resist lift-off process. Fig. 6 (a) shows a partial cross-section of the fabricated Zn-Fe ferrite spiral inductor embedded in organic interposer.

On the other hand, the hybrid core spiral inductor had the same spiral coil as the Zn-Fe ferrite core inductor. However, a via-contact hole at the center pad of spiral coil cannot be realized to the composite core because of metal-mask printing. To solve the problem, a copper pillar was formed at the center pad of

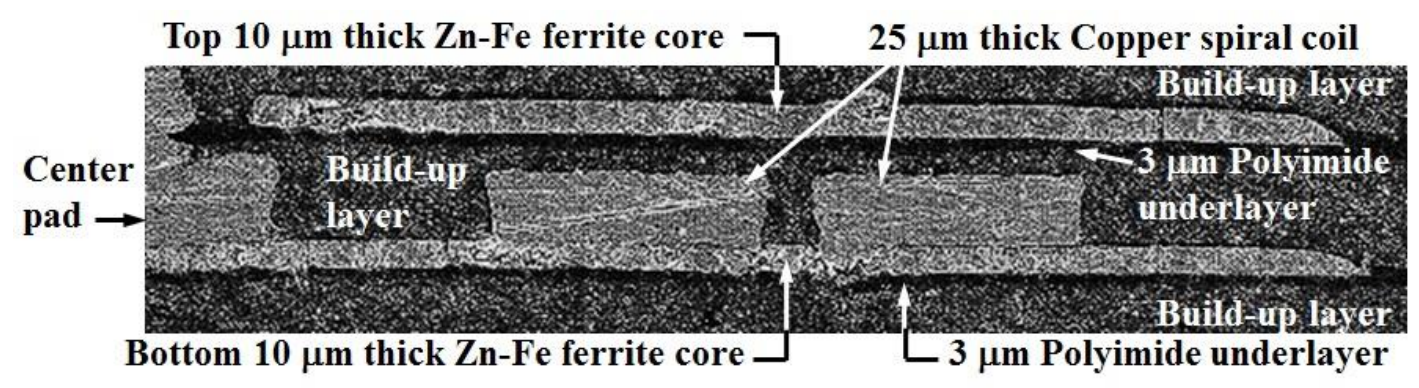

(a) Zn-Fe ferrite core planar spiral inductor

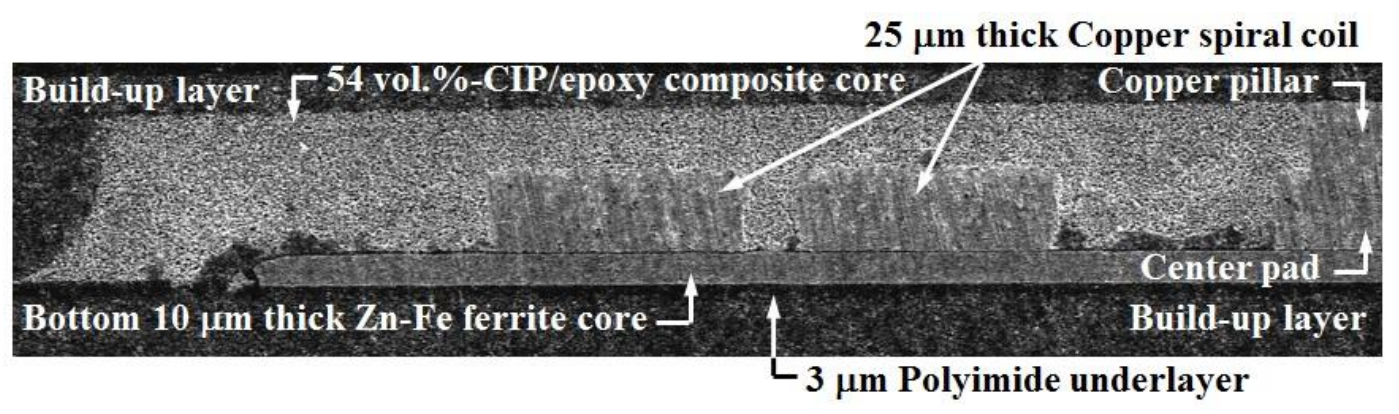

(b) Hybrid core planar spiral inductor

Fig. 6 Fabricated two types of planar spiral inductors embedded in organic interposer package. 
the spiral coil by additional electroplating. The composite core was formed directly on the spiral coil using a $50 \mu \mathrm{m}$ thick SUS-304 metal-mask, and then composite core surface was polished together with copper pillar. A partial cross-section of the fabricated hybrid core spiral inductor embedded in organic interposer is shown in Fig. 6 (b). The thickness of top composite core on copper conductor line was about $30 \mu \mathrm{m}$.

\section{EXPERIMENTAL RESULTS AND DISCUSSION}

\section{A. Inductance and $Q$ Factor vs. Frequency}

Fig. 7 shows the electrical characteristics of the fabricated planar spiral inductors. The result of a 2-turn air-core spiral inductor is also shown in the figures. In Fig. 7 (a), $\mathrm{Zn}$-Fe ferrite core inductor had $5.6 \mathrm{nH}$ inductance at $50 \mathrm{MHz}$, which was 3.1 times larger than that of air-core inductor. On the other hand, hybrid core inductor had $6.6 \mathrm{nH}$ inductance at $50 \mathrm{MHz}$, which was $25 \%$ larger than that of Zn-Fe ferrite core inductor and 3.7 times larger than that of air-core inductor. In Fig. 7 (b), $Q$-factor of the hybrid core inductor was 16 at $50 \mathrm{MHz}$, which was $36 \%$ higher than that of $\mathrm{Zn}$-Fe ferrite core inductor. Such a higher $Q$-factor was considered to be due to the quasi closed magnetic circuit contributing to reduce the high frequency copper loss.

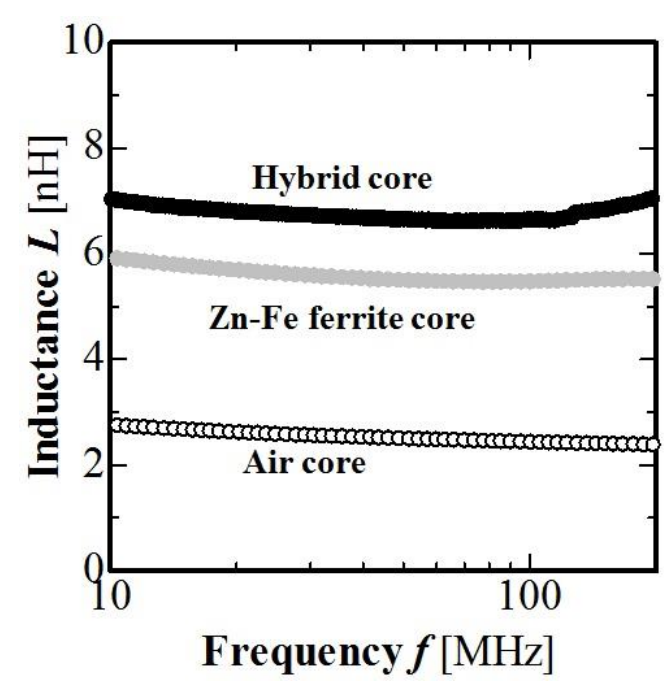

(a) Inductance $v s$. frequency

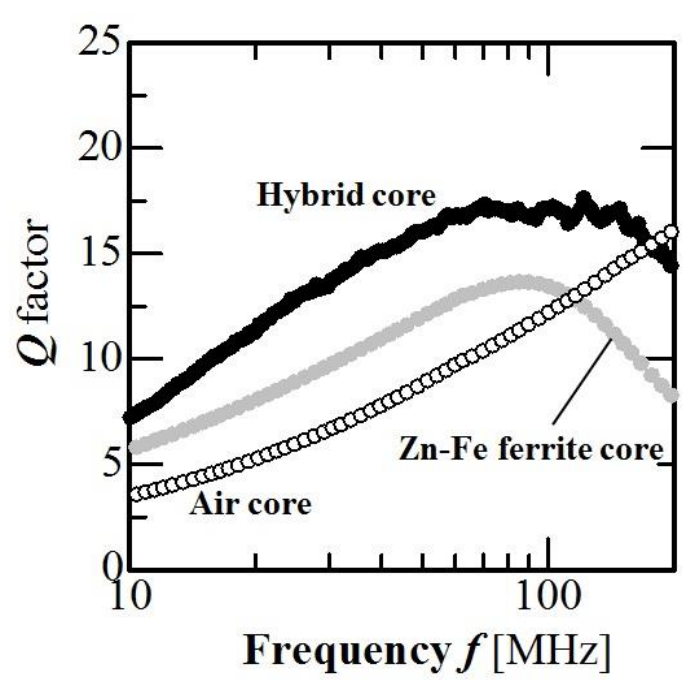

(b) $Q$ factor $v s$. frequency

Fig. 7 Frequency characteristics of two types of the fabricated planar spiral inductors embedded in organic interposer package. 


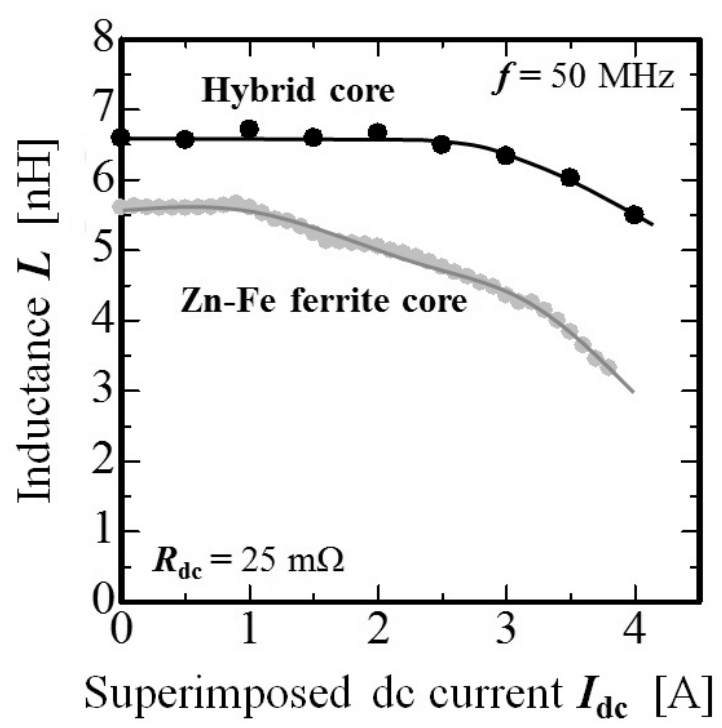

Fig. 8 Superimposed dc current characteristics of two types of the fabricated planar spiral inductors embedded in organic interposer package.

\section{B. Superimposed DC Current Characteristic}

Fig. 8 shows the superimposed dc current characteristics of the fabricated inductors measured at 50 $\mathrm{MHz}$ in frequency. The inductance of hybrid core inductor was constant even when the superimposed dc current increased up to $3 \mathrm{~A}$. Such an excellent superimposed dc current characteristic was considered to be due to the low-permeability carbonyl-iron/epoxy composite core.

To investigate the magnetic flux density distribution of the magnetic core used in the inductor when flowing superimposed dc current $I_{\mathrm{dc}}$, non-linear magnetic field analysis (JMAG Studio, JSOL Co.) was done.

Fig. 9 shows the magnetic flux density distribution of the magnetic core when superimposed dc current $I_{\mathrm{dc}}$ is 4 A. Fig. 9(a) is in case of the $\mathrm{Zn}-\mathrm{Fe}$ ferrite core inductor and (b) is in case of the hybrid core inductor. In Fig. 9(a), the maximum flux density $B_{\max }$ at $I_{\mathrm{dc}}$ of $4 \mathrm{~A}$ in the ferrite core was very close to the saturation magnetization $M_{s}$ of 0.57 T. From the results of Figs. 8 and 9(a), it was considered that the $\mathrm{Zn}-\mathrm{Fe}$ ferrite core inductor had a typical rating dc current of about $2 \mathrm{~A}$ at a $10 \%$ inductance drop. As shown in Fig. 9(b), in the hybrid core inductor, the maximum flux density $B_{\max }$ at $I_{\mathrm{dc}}$ of $4 \mathrm{~A}$ in the top composite core was $0.3 \mathrm{~T}$, this was about $28 \%$ of the saturation magnetization $M_{s}$ of $1.08 \mathrm{~T}$. Therefore, low-permeability composite core exhibited enough margin for the core saturation even at $4 \mathrm{~A}$ superimposed dc current. On the other hand, the maximum flux density $B_{\max }$ at the same $I_{\mathrm{dc}}$ in the bottom $\mathrm{Zn}-\mathrm{Fe}$ ferrite core was $0.5 \mathrm{~T}$, this was close to the saturation magnetization $M_{s}$ of $0.57 \mathrm{~T}$. Hence, it was considered that the low-permeability composite core played an important role of the constant inductance 


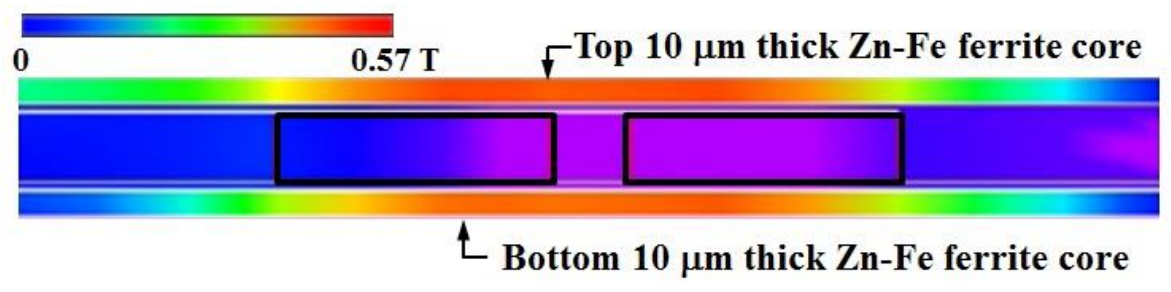

(a) Zn-Fe ferrite core planar spiral inductor

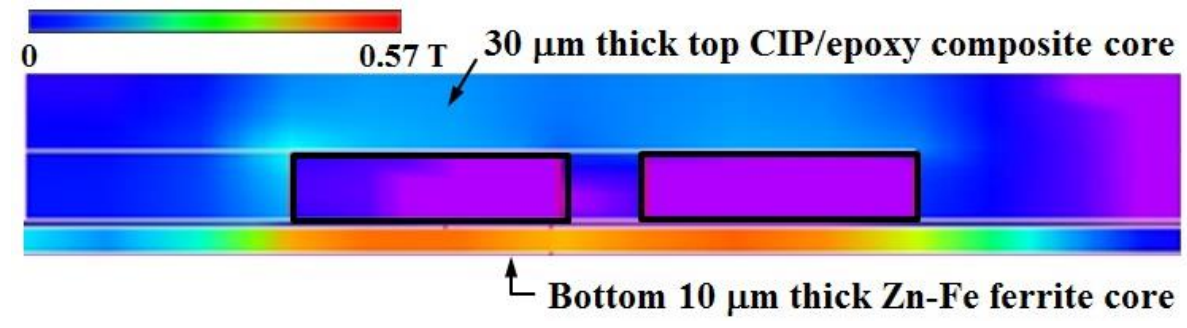

(b) Hybrid core planar spiral inductor

Fig. 9 Magnetic flux density distribution in two types of planar spiral inductors, obtained by non-linear 3D magnetic field analysis (JMAG-Studio).

when increasing superimposed dc current up to around $3 \mathrm{~A}$.

\section{CONCLUSION}

To realize a PLPG, a Zn-Fe ferrite core and a hybrid core planar spiral inductors have been fabricated, which have been embedded in the organic interposer. The fabricated inductors had $1 \mathrm{~mm} 2$ foot-print, 25 $\mu \mathrm{m}$ thick, and 2-trun copper spiral coil. The hybrid core inductor exhibited $6.6 \mathrm{nH}$ inductance at $50 \mathrm{MHz}$, which was $25 \%$ larger than that of the $\mathrm{Zn}-\mathrm{Fe}$ ferrite inductor, and its $Q$-factor was 16 , which was $36 \%$ higher than that of the $\mathrm{Zn}-\mathrm{Fe}$ ferrite inductor. Such an excellent $Q$-factor was considered to be mainly due to the embedded inner spiral in the composite core and bottom $\mathrm{Zn}-\mathrm{Fe}$ ferrite core. In addition, the rating $\mathrm{dc}$ current of the hybrid core inductor was $3.5 \mathrm{~A}$ at $10 \%$ inductance drop, which was about 1.8 times larger than that of the $\mathrm{Zn}-\mathrm{Fe}$ ferrite core inductor. The organic interposer fabrication process usually includes the build-up layer lamination and the copper metallization. Although this paper concludes that the hybrid core inductor is superior to the ferrite core inductor, the ferrite core inductor has a great advantage, that is, it can be embedded easily in the organic interposer by adding ferrite deposition process only to the usual organic interposer process without excess cost increase.

\section{ACKNOWLEDGMENT}

This work was supported by a Grant-in-Aid for Scientific Research of Japan Society for the Promotion of Science under Grant 24560328. 


\section{REFERENCES}

[1] International Workshop on Power Supply on Chip (Power SoC2012), San Francisco, CA, USA. (2012) [Online]. Available: http://powersoc2012.org/

[2] P. Hazucha et al., "A 233-MHz 80\%-87\% efficient four-phase DC-DC converter utilizing air-core inductors on package," IEEE J. Solid-State Circuits, vol. 40, no. 4, pp. 838-845, Apr. 2005.

[3] K. Onizuka, K. Inagaki, H. Kawaguchi, M. Takamiya, and T. Sakurai, "Stacked-chip implementation of on-chip buck converter for distributed power supply system in SiPs," IEEE J. Solid-State Circuits, vol. 42, no. 11, pp. 2404-2410, Nov. 2007.

[4] Y. Sugawa, K. Ishidate, M. Sonehara, and T. Sato, "Carbonyl-iron/epoxy composite magnetic core for planar power inductor used in package-level power grid," IEEE Trans. Magn., vol. 49, no. 7, pp. 4172-4175, Jul. 2013.

[5] T. Fujii et al., "Planar power inductor with magnetic film for embedded LSI package," in Proc. 45th Int. Symp. Microelectron., Sep. 2011.

[6] T. Sato et al., "Magnetic core power inductor embedded in plastic interposer toward power supply integrated in LSI package,” presented at the IEEE Power Electronics Society, International Workshop on Power Supply on Chip (PowerSoC2012), San Francisco, CA, USA, 2012.

[7] M. Abe, "Ferrite-film formation from an aqueous solution, and its application," (in Japanese), J. Magn. Soc. Jpn., vol. 22, no. 9, pp. 1225-1232, 1998.

[8] K. Hagita et al., "Magnetic properties of spin-sprayed ferrite film deposited on glass/epoxy build-up layer in organic interposer substrate," in Proc. 11th ICF, 2013, pp. 17-51.

[9] [Online]. Available:http://www.monomers.basf.com/cm/internet/en/function/conversions:/publish/content/ Produkte/Metallsysteme/CIP/1958_FL_CIP_IEC_RZ.pdf

[10] M. Koeda, A. Harada, H. Ono, T. Ishikura, T. Kuroda, and H. Moro, "Research of carbonyl iron powder for development of the power inductor for high frequency," (in Japanese), IEEJ Trans. Fundam. Mater., vol. 131, no. 11, pp. 949-954, 2011.

[11] G. Herzer, "Grain size dependence of coercivity and permeability in nanocrystalline ferromagnets," IEEE Trans. Magn., vol. 26, no. 5, pp. 1397-1402, Sep. 1990. 